\title{
Pulmonary Presentation of Atypical Kawasaki Disease
}

\author{
Jaikumar Govindaswamy Ramamoorthy ${ }^{1}$ (D) Avinash Anantharaj $^{2}$
}

Received: 25 August 2020 / Accepted: 25 November 2020 / Published online: 8 January 2021

(C) Dr. K C Chaudhuri Foundation 2021

To the Editor: A 19-mo-old boy presented with fever, cough, rhinorrhoea and respiratory distress for $2 \mathrm{~d}$. On examination the child was interactive and alert, febrile $\left(101^{\circ} \mathrm{f}\right)$ with tachypnoea, had chest indrawing and diffuse crepitations in bilateral chest regions. The child did not have rash, conjunctival congestion, lymphadenopathy or peripheral edema. Systemic examination was unremarkable. The oxygen saturation on room air was $84 \%$ and $97 \%$ with $40 \%$ oxygen supplementation. Chest roentgenogram showed bilateral hyperinflation with diffuse reticulonodular infiltrates (RNI) (Fig. 1a). Polymerase chain reaction for SARS-CoV-2, influenza, respiratory syncytial and cytomegalovirus were negative. The investigation done on day 4 and day 8 of illness are given in Table 1 which showed worsening trends of the markers of inflammation. Evaluation for tuberculosis, scrub typhus, urine and blood cultures were all non-contributory. Because of persistent distress and fever, echocardiogram was performed on day 8 which revealed aneurysm of left main coronary artery $(3.7 \mathrm{~mm} ; 5.62 \mathrm{Z}$ score $)$ and dilatation of left anterior descending artery $(2.2 \mathrm{~mm} ; 2.48 \mathrm{Z}$ score $)$ with the laboratory markers of Kawasaki disease (KD) were in worsening trend. He became afebrile and distress-free within $36 \mathrm{~h}$ of intravenous immunoglobulin (IVIG) therapy and aspirin at $50 \mathrm{mg} / \mathrm{kg} / \mathrm{d}$ for $2 \mathrm{~d}$ followed by $3 \mathrm{mg} / \mathrm{kg} / \mathrm{d}$ (anti-platelet dose). Roentgenogram done 5 $\mathrm{d}$ after IVIG showed clearing of RNI (Fig. 1b). There was

Jaikumar Govindaswamy Ramamoorthy gr_jaikumar@yahoo.in

1 Department of Pediatrics, Jawaharlal Institute of Postgraduate Medical Education and Research (JIPMER), Puducherry 605006, India

2 Department of Cardiology, Jawaharlal Institute of Postgraduate Medical Education and Research (JIPMER), Puducherry, India no periungual peeling or nail changes at week 2 of followup with normal systemic examination. Echocardiogram after 8 wk showed normal coronary arterial dimensions and anti-platelet dose of aspirin was stopped at $8 \mathrm{wk}$. The general and systemic examination was unremarkable at this point.

The diagnosis of incomplete KD has three sequential steps [1]. Our index case never followed the sequence and only had coronary artery abnormalities (CAA) without compatible clinical and laboratory feature which was perplexing to us. Occasional cases of mild CAA (2.5-5 $\mathrm{Z}$ score) have been reported in non-KD febrile illness but moderate CAA have never been [2-4]. The presence of moderate CAA rules out non-KD febrile illness in our case.

The incidence of pulmonary presentation of $\mathrm{KD}$ has been $1.83 \%$ in a retrospective cohort [5]. Bronchopneumonia was the commonest pulmonary manifestation, though pneumothorax, pleural effusion and empyema have been observed. The first clinical sign of KD was observed after a mean duration of 14.5 $\mathrm{d}$ from onset of clinical symptoms. Unresolved fever and distress with abnormal laboratory markers only aroused the suspicion of $\mathrm{KD}$ in this cohort [5]. Diagnosing KD in a child with isolated pulmonary presentation is always challenging when classical features of $\mathrm{KD}$ are absent. Worsening trends of hemogram, liver function test and inflammatory markers in a child with unresolving and unexplained fever and respiratory distress is a pointer of incomplete $\mathrm{KD}$. It may be too late to diagnose and treat $\mathrm{KD}$ after the diagnostic cut-off point for laboratory values are reached, especially whenever the child has a compatible clinical setting.

Persistent fever with unexplained distress $\geq 7 \mathrm{~d}$ with RNI in roentgenogram should arouse a suspicion of incomplete KD. Worsening trends of inflammatory markers, even when not meeting the diagnostic cut-off, might be the earliest marker for $\mathrm{KD}$ in these children with isolated pulmonary presentation. 
Fig. 1 Chest roentgenogram (a) on day of admission showing bilateral hyperinflation with diffuse dense reticulonodular infiltrates, (b) done $5 \mathrm{~d}$ after intravenous immunoglobulin administration showing persistent bilateral hyperinflation but with clearance of reticulonodular infiltrates

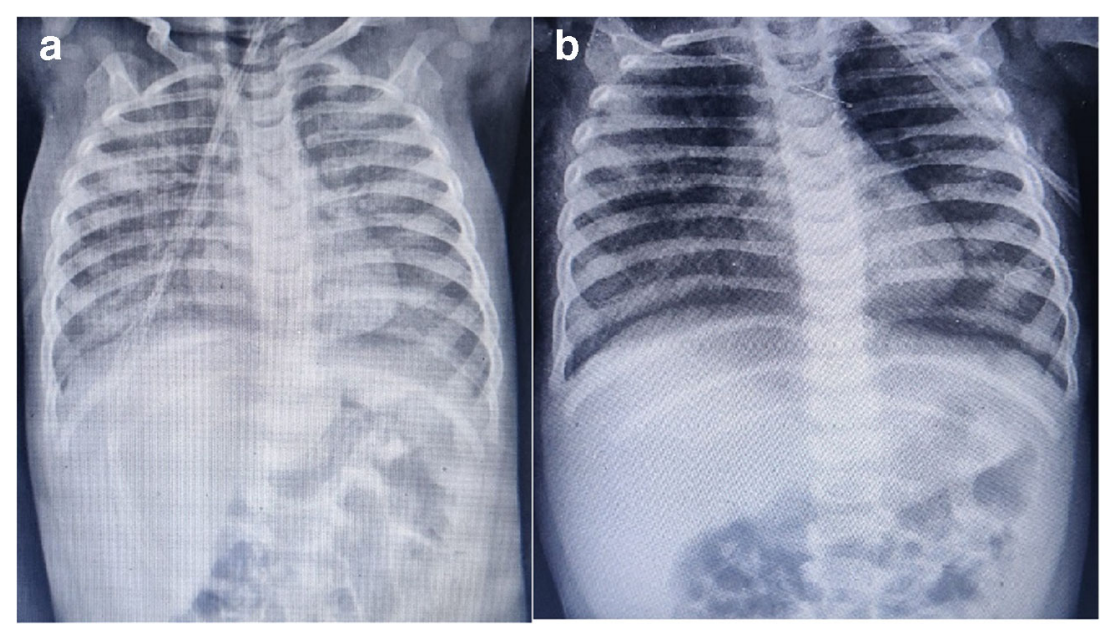

Table 1 Laboratory reports on day 4 and 8 of illness

\begin{tabular}{lll}
\hline Investigation & Day 4 of illness & Day 8 of illness \\
\hline Hemoglobin $(\mathrm{g} / \mathrm{dL})$ & 9.6 & 9.1 \\
Mean corpuscular volume $(\mathrm{fl})$ & 61 & 56 \\
Total leucocyte count $\left(\times 10^{3} / \mu \mathrm{L}\right)$ & 16.5 & 18.7 \\
Platelet count $\left(\times 10^{3} / \mu \mathrm{L}\right)$ & 312 & 402 \\
Erythrocyte sedimentation rate $(\mathrm{mm} / \mathrm{h})$ & 28 & 35 \\
C-reactive protein $(\mathrm{mg} / \mathrm{dL})$ & 0.9 & 1.2 \\
Urine microscopy & No leucocytes & No leucocytes \\
Serum albumin $(\mathrm{g} / \mathrm{dL})$ & 3.5 & 3.1 \\
Aspartate transaminase $(\mathrm{U} / \mathrm{l})$ & 31 & 34 \\
\hline
\end{tabular}

\section{Compliance with Ethical Standards}

\section{Conflict of Interest None.}

\section{References}

1. McCrindle BW, Rowley AH, Newburger JW, et al. Diagnosis, treatment, and long-term management of Kawasaki disease: a scientific statement for health professionals from the American Heart Association. Circulation. 2017;135:e927-99.

2. Muniz JC, Dummer K, Gauvreau K, Colan SD, Fulton DR, Newburger JW. Coronary artery dimensions in febrile children without Kawasaki disease. Circ Cardiovasc Imaging. 2013;6:239-44.
3. Bratincsak A, Reddy VD, Purohit PJ, et al. Coronary artery dilation in acute Kawasaki disease and acute illnesses associated with fever. Pediatr Infect Dis J. 2012;31:924-6.

4. Asi K, Gourishankar A, Kamdar A. Coronary artery dilation associated with anti-synthetase syndrome in an adolescent. Pediatr Rheumatol Online J. 2019;17:3.

5. Singh S, Gupta A, Jindal AK, et al. Pulmonary presentation of Kawasaki disease-a diagnostic challenge. Pediatr Pulmonol. 2018;53:103-7.

Publisher's Note Springer Nature remains neutral with regard to jurisdictional claims in published maps and institutional affiliations. 